\title{
La vida que inútilmente se consume en la llama. Imagen, Gesto y Política: Giorgio Agamben y Guy Debord
}

\section{The Life that Usselesly Consumed in the Flame. Image, Gesture and Politics: Giorgio Agamben and Guy Debord}

\author{
Rodrigo Karmy Bolton \\ Universidad de Chile
} rodrigokarmy1977@gmail.com

Resumen: El presente ensayo muestra la influencia del trabajo de Guy Debord en el pensamiento de Giorgio Agamben, en particular, en lo que se refiere a uno de los núcleos de su pensamiento, esto es, la diferencia entre "imagen" y "gesto". Para ello, se recurrirá a tres momentos de su trabajo, partiendo por las "Glosas a los Comentarios de la Sociedad del espectáculo" escritas en I993, pasando por "El Reino y la Gloria", del año 2007, y terminando en "El Uso de los cuerpos", de 20I4. En los tres momentos existen breves referencias a Debord que, sin embargo, conducirán a Agamben a la cuestión del "gesto" o, lo que es igual, a la forma-de-vida.

Palabras clave: imagen, gesto, política, espectáculo, averroísmo.

Abstract: This essay shows the influence of Guy Debord's work on Giorgio Agamben's thought, in particular, regarding one of the central problems of his thought, that is, the difference between "image" and "gesture". To show this, I will used three moments of his work, starting 
with "Glosas to the Comments of the Society of the spectacle" written in 1993 to go further to "The Kingdom and the Glory", of 2007, and ending in "The Use of the Bodies", of 20r4. In these three moments we could find three references to Debord that, nevertheless, will lead Agamben to the question of the "gesture" or, as it is known, the problem of the "form-of-life".

Keywords: Image, Gesture, Politics, Spectacle, Averroism.

Recibido: I de abril de $202 \mathrm{I}$ Aceptado: 25 de agosto de $202 \mathrm{I}$ https://dx.doi.org/IO.I 5 I 74/rv.vi 4i29.6I 8

El espectáculo es el capital en un grado tal de acumulación que se ha convertido en imagen.

Guy Debord, La SociedAd DEL ESPECTÁCulo

\section{Debord}

Todos los conceptos agambenianos son conceptos debordianos gestualizados. Citado al margen de sus genealogías en torno a la gloria, en alguno que otro escrito titulado "Glosas" o al inicio del último libro de la saga Homo Sacer (El "Uso de los cuerpos") la irrupción de Debord en la trama filosófica agambeniana está lejos de ser algo menor y, más bien, constituye un pivote decisivo de su reflexión. Si es cierto que Agamben desarrolla gran parte de su "arqueología filosófica" (Agamben, 2008) a partir de los desarrollos propuestos por Debord, es fundamentalmente porque en él, la cuestión de la "imagen" y el "gesto" constituirán dos elementos críticos que 
articulan al trabajo agambeniano y que, a partir de Debord, la permitirán al italiano dos operaciones: por un lado, la denuncia más cruda y directa de la espectacularización del planeta por la cual la mercancía ha podido devenir "imagen” (Debord, 2002); por otro, el relato de algunas peripecias de la vida de Debord en las que no solo se cuela una época que desgarró las referencias clásicas sobre las que se sostenía la sociedad (Debord, 2009), sino un aspecto "clandestino" -dice Agamben en 2014- que constituirá el más precioso secreto de la política (Agamben, 2014). Debord irrumpe como un demonio de dos cabezas: por un lado, quien diagnostica el completo cierre de una época histórica en la forma de la sociedad del espectáculo; por otro, quien abre nuevas posibilidades para pensar la política, en medio de su completa devastación.

A continuación, me enfocaré en tres textos de Agamben que van desde 1993 hasta el 2014 en los que Debord aparece bajo esa doble forma: en primer lugar, "Glosas marginales a los Comentarios sobre la Sociedad del Espectáculo” (1993); en segundo lugar, una referencia breve, pero precisa en "El Reino y la Gloria. Una genealogía de la economía y del gobierno" (2007) y, en tercer lugar, la introducción a "El Uso de los Cuerpos" (2014) en la que Agamben deja de lado el diagnóstico sobre el "espectáculo" para, a través de Debord, pasar directamente a pensar la cuestión de la forma-de-vida.

Propongo pensar los tres textos mencionados a partir de la tensión entre "imagen (representación-mercancía)" y "gesto" (medialidad pura) o, si se quiere, entre "vida desnuda" y "forma-de-vida": si la primera constituye una producción "original" del poder soberano (Agamben, 2003), la segunda devendrá un "punto de indiferencia” en que, más allá de la clásica distinción aristotélica respecto del "hacer" que establecía la diferencia entre poiesis y praxis, la forma-de-vida asoma como el verdadero "gesto" que, no apunta a ser un medio para un fin (poiesis), ni tampoco a clausurarse como 
un fin en sí mismo (praxis), sino que pretende exponer: "el ser en el lenguaje del hombre" (Agamben, 2001: 55) como un medio puro y sin fin.

Esa vida -dirá Agamben- no "produce” ni "actúa”, pero irrumpe como un "punto de indiferencia" en que la "clandestinidad" de la vida descrita por Debord en "Panegírico" no se deja devorar por la transparencia total y la extensión global de la sociedad del espectáculo (Debord, 2009). Justamente, esa vida, que algunos dieron nombre de "beatitud" y otros de "vida feliz", es la que no "produce" ni "actúa" pues su eternidad remite a un (des) centro inoperoso cuyo vivir consiste única y exclusivamente en una vida que se consume inútilmente en la llama.

\section{Espectáculo}

"La separación es alfa y omega del espectáculo" (Debord, 2002). Clave en este sentido es que la palabra "separación" es destacada por el propio Debord. Todo el arsenal espectacular funciona como un dispositivo de separación y, de manera más precisa, de transformación de todo gesto en imagen, es decir, en la tautología de la representación que se representa a sí misma.

Para Agamben, "La sociedad del espectáculo" aparece como un "manual" o un "instrumento" que concierne al juego de la estrategia. A ojos de Agamben, Debord constituye un "estratega singular” porque no plantea qué se debe hacer, y qué tropas habrá que mover, sino más bien, su "campo de acción" remitiría a la "pura potencia del intelecto": la referencia averroísta es, en este sentido, clave para entender porqué Debord asume el carácter de "estratega singular"; es preciso entender que sus textos no han de ser leídos como obras acabadas que contengan puntos de vista "externos" a la experiencia, sino más bien, escrituras que devienen experiencia precisamente porque no hacen "obra", sino que constituyen pe- 
queños juegos capaces de suspender los continuums de la maquinaria espectacular.

Será por esta razón que "La sociedad del espectáculo" constituye una pieza fundamental para la crítica del presente. Un pequeño "manual" de resistencia que nos insta a salir de nosotros mismos y situarnos en otro lugar; un "campo de acción” que no remite más que a la "pura potencia del intelecto" que, en cuanto medio puro, puede adquirir múltiples formas de uso, diferentes lecturas que dependerán estrictamente de la situación en la que nos encontremos. No se trata, por tanto, de cualquier estrategia, sino de una "singular" - dice Agamben- que traen: "manuales o instrumentos para la resistencia o para el éxodo" (Agamben, 2001: 63).

En su perspectiva, la cuestión decisiva que aborda Debord en "La sociedad del espectáculo" fue el haber desarrollado con todas las posibilidades de su tiempo el pequeño apartado al primer tomo de "El Capital" de Marx titulado "El fetichismo de la mercancía". Si este último, había sido desdeñado por una cierta tradición marxista (desde Lenin hasta Althusser), Debord justamente recupera ese apartado para desplegar desde ahí la crítica a la "sociedad del espectáculo" donde: "El devenir-imagen del capital no es más que la última metamorfosis de la mercancía”, dice Agamben. Será precisamente en dicha "metamorfosis" donde el "valor de cambio" ha logrado eclipsar" por completo al "valor de uso" y donde toda imagen deviene, entonces, parte de la "falsificación" generalizada de "toda la producción social".

A partir de Debord, Agamben se distancia, entonces, de un cierto marxismo para plantear lo que a sus ojos le parece la cuestión más decisiva de todas: la capacidad del capitalismo residía no solo en expropiar la producción material sino, sobre todo, la gestualidad integral de los seres humanos: 
Porque está claro que el espectáculo es el lenguaje, la comunicabilidad misma y el ser lingüístico del hombre. Y esto significa que el análisis marxiano debe ser completado en el sentido de que el capitalismo (o cualquier otro nombre que se quiera dar al proceso que domina hoy la historia mundial) no se dirigía solo a la expropiación de la actividad productiva, sino también y sobre todo a la alienación del propio lenguaje, de la propia naturaleza lingüística y comunicativa del hombre, de ese lógos que un fragmento de Heráclito identifica con lo Común. La forma extrema de esta expropiación de lo Común es el espectáculo, es decir la política en que vivimos (Agamben, 2001: 70-71).

Si el lenguaje caracteriza nuestra experiencia de lo Común, el espectáculo será el modo de su "expropiación” en la medida que hace que la "esencia genérica" del lenguaje quede separada en "una esfera autónoma" que hace que los hombres "estén separados por lo que les une" (Agamben 2001: 72). Siguiendo de cerca la referencia debordiana, según la cual, la "separación es el alfa y omega del espectáculo", Agamben, por cierto, vuelve a la lectura de los "Manuscritos de 1844 de Marx" que había desarrollado en su primer libro "El hombre sin Contenido" en el que destacaba, tal como hará aquí, la "esencia genérica” del hombre que define a su carácter Común y cómo el espectáculo termina separando esa esfera respecto de los hombres mismos. Las palabras se burocratizan, pierden la potencia con las que fueron pronunciadas, el gesto con el que abrían posibilidades y operan como simples referencias automáticas sin posibilidades de gestualidad. A esta luz, el espectáculo pareciera "sacralizar" completamente al ser lingüístico del hombre, en la medida le separa de su naturaleza y, en último término, les priva de una ética posible: los hombres quedan mudos y reducidos a una "vida desnuda" mientras que el espectáculo habla ininterrumpidamente sin producir ninguna experiencia singular. 
Reducidos a vidas desnudas con el ser lingüístico erigido en esfera autónoma identificada plenamente al capital, las palabras pierden su potencia reveladora y la comunicación queda completamente escindida de su comunicabilidad. Por cierto, la "glosa" que desarrolla Agamben aquí sobre la hipótesis de Debord adelanta las diferentes aproximaciones contemporáneas al "capitalismo de plataformas" (Srincek, 2018) o a la "hipótesis cibernética" (Tiqqun, 2001) pero pone el énfasis en la mutación antropológica experimentada, en el hecho de que la esfera de los medios puros a la que pertenece el lenguaje (y, por cierto, la política), ha terminado por quedar capturada en las formas del capitalismo espectacular, la nueva "religión" cuyo único dogma -dirá Debord- no es sino el del cambio perpetuo (Debord, 2002).

\section{Gloria}

La crítica a la sociedad del espectáculo otrora abierta por Debord encuentra su desarrollo más acabado en "El Reino y la Gloria. Una genealogía teológica de la economía y del gobierno, Homo sacer II, 2" publicado por Giorgio Agamben en el año 2007. Como es sabido, en este libro el filósofo italiano desarrolla la otra cara de la máquina jurídico-política que había sido trabajada en las secciones de "Homo sacer" precedentes, esto es, la dimensión propiamente "gubernamental".

Premunido de la lectura que ofrecen los recientes cursos de 1978 en el Collège de France pronunciados por Michel Foucault en los que desplaza la noción de "biopolítica" por la de "gubernamentalidad" (Foucault, 2008), Agamben prosigue la genealogía foucaulteana remitiéndose, sin embargo, al ámbito de la teología cristiana. Para Foucault la "gubernamentalidad" constituía una forma novedosa de ejercicio del poder inaugurada fundamentalmente a partir del liberalismo, ella consistía en hacer de la "econo- 
mía” la matriz del ejercicio del poder donde la genealogía del "poder pastoral cristiano" habría operado como una "línea de fuerza" antinómica a la clásica forma de soberanía al interior de la historia del poder en Occidente (Foucault, 2008).

Agamben complementará el análisis más allá de las prácticas referidas al "poder pastoral cristiano" y subrayando cómo es que la teología cristiana, en su elaboración de la "gloria” posibilitó la aparición de esta novedosa forma de poder: “¿Por qué el poder necesita de la "gloria"?" (Agamben, 2007), se pregunta. Y la respuesta no se hace esperar: el poder en su forma gubernamental no es más que la performance gloriosa. En este sentido, la referencia agambeniana a la teología no intenta indagar acerca "de qué es la gloria", sino más bien, reformula la pregunta para investigar no la "esencia" de la gloria, sino las "formas de glorificación". Por tanto, no se trata de una indagación "teológica" sino "genealógica" que indaga sobre el modo en que se habría ensamblado la "máquina gubernamental" cuya forma extrema lo constituiría su deriva espectacular.

En el léxico agambeniano, una "máquina” es un dispositivo compuesto de dos polos antinómicos, pero integralmente complementarios entre sí, en cuyo centro se anuda un vacío. Toda máquina no hará más que invisibilizar su propio vacío, su misma falta de "sustancia”. Y, sin embargo, esa misma maquinaria no producirá otra cosa que la ilusión de que el "trono" está ocupado, lleno por algún soberano, aun cuando ese "trono" está constitutivamente vacío y desnuda la dimensión inoperosa de la vida. Siguiendo el léxico paulino, Agamben retomará la noción de zoé aionós (vida eterna) para designar la dimensión inoperosa capaz de desactivar la máquina gubernamental y revocar enteramente la gloria. Este sería la "posibilidad positiva" que el propio Agamben había advertido en sus "Glosas" de 1993 y que remitirán al problema del gesto -a diferencia de la cuestión de la imagen- que exploraremos en el siguiente apartado. 
Por ahora, profundicemos el análisis que nos propone Agamben: si la gloria no debe ser vista en su dimensión "teológica" sino "genealógica" ¿cómo debe entenderse? Ante todo, "gloria" coincide con las múltiples formas de alabanza y aclamaciones eficaces que constituyeron a los signos que usa el poder y que, como mostrará Agamben, implicarán una identidad constitutiva entre poder y glorificación, en la medida que ambos no son otra cosa que la performance que produce infinitos y múltiples signos de poder. Es precisamente en este punto que la genealogía agambeniana amplía el análisis debordiano propuesto en la "sociedad del espectáculo":

"Lo que en una época estaba confinado a las esferas de la liturgia y los ceremoniales, se concentra en los medios masivos y, a la vez, a través de ellos, se difunde y penetra a cada instante y en cada ámbito de la sociedad, tanto público como privado. La democracia contemporánea es una democracia basada integralmente en la gloria, es decir, en la eficacia de la aclamación, multiplicada y diseminada por los medios masivos más allá de toda imaginación" (Agamben, 2008: 446).

La modernidad habría emancipado, entonces, al dispositivo de glorificación ensamblado por la teología cristiana y que lo había mantenido circunscrito al exclusivo ámbito de las "liturgias y ceremoniales". Es precisamente en esta genealogía donde Agamben hace converger la investigación foucaulteana en torno al "gobierno" y la producción de "verdad" (Foucault, 2008), la schmittiana en torno a la "aclamación" en la democracia moderna (Schmitt, 2006) y la debordiana en torno a la "sociedad del espectáculo" (Debord, 2003): gobierno, aclamación y espectáculo constituyen la tríada conceptual a partir de la cual podremos concluir que no será la soberanía, sino el gobierno, la figura del ángel y no la de Dios, el arcano último del poder cuya performatividad se resuelve nada más que en las múltiples formas de glorificación que constituyen el dispositivo "promiscuo" que posibilita el cruce entre 
cielo y tierra, entre excepción y derecho que, ocultando el vacío inoperoso de la máquina (su estar constitutivamente articulada en función del "trono vacío"), le hace funcionar permanentemente.

No habrá máquina sin modalidades precisas de glorificación, porque justamente serán estas últimas las que se ensamblan como máquina. En otros términos, es el dispositivo glorioso el que mantiene unidos y separados a la soberanía y al gobierno que en las "democracias gloriosas" contemporáneas se han emancipado radicalmente del lugar circunscrito al que lo había reducido la teología cristiana, totalizando así, todos los aspectos de la vida social.

Todo este planteamiento nos da la oportunidad de mostrar la profundización que Agamben ya había desarrollado en las "Glosas" en torno a Guy Debord hasta articular una genealogía "teológica" que permite evidenciar por qué ha triunfado la sociedad del espectáculo, es decir, por qué la "imagen" (entendida como representación) habría terminado por sustituir al gesto. Y si bien, la cuestión del "gesto" aparece en "El Reino y la Gloria" a partir de la figura paulina de la zoé aionós, será justamente en torno a dicho problema que tendremos que volver y mostrar cómo es que Debord no solo permite a Agamben pensar en su "genealogía" de la gloria, sino que también, en la "posibilidad positiva" del "gesto" (zoé aionós) que permanece como resto irreductible a la devastación espectacular.

\section{Gesto}


4. 1 .

En el primer volumen de "Panegírico" Guy Debord escribe:

Después de las circunstancias que acabo de evocar, lo que sin duda marcó mi vida entera fue el hábito de beber, que adquirí rápidamente. Los vinos, los licores, y las cervezas; los momentos en que unos se imponían a otros o los momentos en que se repetían, fueron trazando el curso principal y los meandros de los días, de las semanas, de los ańos [...] Del escaso número de cosas que me han gustado y he sabido hacer bien, lo que seguramente he sabido hacer bien es beber (Debord, 2009: 75).

Como en sus "Glosas" de 1993 en las que Agamben subrayaba cómo, a pesar de la "alienación del ser lingüístico del hombre" producida por la deriva de la sociedad del espectáculo, permanecía una "posibilidad positiva" como remanente en la que se libera una potencia no acontecida, otrora capturada por la máquina: una observación de Agamben al respecto es absolutamente clave en el Prólogo a "El Uso de los cuerpos", donde el italiano cuenta cómo "en las mesas de una librería parisina” encontró dos libros (Agamben, 2014): por un lado, el segundo volumen de "Panegírico" de Debord que, como se sabe está plagado de fotografías y, por otro, la autobiografía de Paul Ricoeur. Las fotografías presentes en el libro de Ricoeur "retrataban al filósofo únicamente durante congresos académicos" (Agamben, 2014: 16) el segundo volumen de "Panegírico" se compone de fotografías que retratan a Debord en su "verdad biográfica” y así, la vida en "todos sus aspectos", tal como ilustra el pasaje que acabo de citar, Debord expone la banalidad de la vida, que se asoma en una mirada "clandestina" a toda máquina: el relato debordiano expone la selva cotidiana de la vida, el fragor de sus derrotas, malestares y placeres en medio de una 
época tormentosa que, en sus palabras, dejó atrás todas las "referencias clásicas" y donde la bebida le ha dejado "poquísimo tiempo para escribir" -justamente para mantener el carácter "excepcional" de la escritura-.

El propio Agamben profundiza su observación sobre el aspecto biográfico destacado por Debord aquí: a diferencia de Ricoeur que llenaba de fotografías acerca de su vida pública (en sus congresos de filosofía), en los relatos y fotografías de Debord, advertimos una indecidibilidad entre vida pública y privada $y$, en este sentido -observa Agamben- la vida expuesta por Debord deviene aquí irreductible a la cesura entre vida privada y pública, entre simple biografía e imagen pública. Al contrario, en Debord asistimos a una confusión, un "punto de indiferencia" donde toda la cesura propiciada por la máquina es excedida por la misma vida que irrumpe desde su propio interior y desordena la operatoria, las lógicas y las formas de ejercicio del poder.

¿Qué puede ser la bebida citada en Debord, sino el umbral en el que los seres humanos se encuentran con la inoperosidad de la vida, el antídoto a la "sociedad del espectáculo" que se abre como una potencia que puede expresarse como escritura, danza o, eventualmente, una revuelta? Si se quiere, podemos decir que en la "clandestinidad" de esa vida expuesta por Debord nos encontramos con el umbral en el que las imágenes del espectáculo mediático pueden plasmarse en la inmanencia del gesto.

\section{2 .}

En su texto "Notas sobre el gesto" Agamben plantea, al menos, cinco "notas" en las que algo así como un gesto excede la caducidad maquinal de la imagen a la que el espectáculo ha convertido a la vida (Levitt, 2008). Para ello, Agamben remite al cine; en él, la burguesía intenta recuperar los gestos que habían sido perdidos ya 
en el siglo XIx: "En el cine, una sociedad que ha perdido sus gestos trata de reapropiarse de lo que ha perdido" (Agamben, 2003: 50). Por esta razón el cine no pertenece a la dimensión estética como comúnmente se lo plantea, sino a dimensión de la ética: en el cine la humanidad intentó recuperar los gestos que estaban siendo avasallados, puesto que sus imágenes no son inmóviles, sino que adquieren un elemento "histórico y dinámico" que las vuelve gestos antes que simple representación.

Por esta razón, el cine no tiene como elemento a la "imagen" sino justamente al "gesto": en una "prolongación" de la tesis deleuziana acerca de la "imagen-movimiento", Agamben plantea que esta última define a la imagen misma de la modernidad. Ahora bien, esa "imagen-movimiento" - ese "gesto"- se compone de dos polos antinómicos: en el primero, la imagen lleva consigo un aspecto de reificación en el que se anula al gesto; en el segundo "conserva intacta su dynamis" (Agamben, 2003: 52) en que algo así como un ritmo le ofrece vida a la imagen e impide que ella permanezca como "trabajo muerto" (Marx).

Por cierto, no puede ser casual el uso del término "dynamis" en esta cita: para Agamben una imagen conserva un remanente propio de la "memoria voluntaria", pero a su vez: "surge como un relámpago en la epifanía de la memoria involuntaria” (Agamben, 2003: 52), en cuyo instante se pone en juego una potencia. Este último aspecto es precisamente el de un gesto que ofrece la sobrevida de una potencia que hace vibrar a toda la historia del arte como una lucha desesperada para liberar a la "imagen en el gesto".

En este sentido, la característica más decisiva del gesto es que precisamente en él "no se produce ni se actúa, sino que se asume y se soporta” (Agamben, 2003: 53). Si, como hemos dicho, desde Aristóteles las formas que ha tenido el pensamiento que abordar la cuestión del "hacer" ha sido sea como "producción" en que se juega el hacer de un medio para lograr un fin o sea como "acción" 
que, siguiendo a la tradición peripatética, se define por un "hacer" que remite al fin en sí mismo. Justamente, un gesto "abre la esfera del ethos -dice Agamben- en el que, al igual que Debord en 'Panegírico' con la indecibilidad entre vida privada y pública, se expone una 'medialidad pura y sin fin"”: "El gesto es la exhibición de una medialidad, el hacer visible un medio como tal" (Agamben, 2003: 54). En el gesto, la imagen encuentra vida y los medios sin fin reinan. Es aquí donde resulta importante diferenciar mínimamente entre gesto e imagen: el primero es un medio puro, la segunda, una formación que encuentra su potencia en el primero. Una imagen podría devenir mercancía solo si es separada del gesto. Cuando es abrazada por el gesto, la imagen adquiere potencia pues, en palabras de Agamben, "hace visible al medio como tal". De esta forma, si bien imagen y gesto no pueden considerarse sinónimos, resulta imprescindible atender la mutua imbricación conceptual de la que forman parte. Dos intensidades de una misma forma-de-vida, el gesto y la imagen devienen dos fuerzas compenetradas en el esfuerzo por destituir las políticas de la separación.

Pero ¿qué es un medio sin fin sino el ser lingüístico del hombre que no expresa nada, sino que expone el simple tener lugar del lenguaje, la comunicabilidad misma de toda comunicación? Por eso, todo discurso se ve interrumpido en el gesto. No porque este último sea un simple "vacío" de palabra, sino porque constituye la exposición misma del tener-lugar del lenguaje, su ser medio puro.

"Guy recuerda el desorden, los amigos, los amores", escribe Agamben (2003: 13). Precisamente, Debord muestra su vida como gesto. Mas, exponiéndola así, ella no dice nada, no ofrece lecciones ni juicios, sino que, los hace implosionar y exhibe su medialidad pura, como una completa "falta de obra".

Agamben no entiende por gesto una identificación de la vida en el arte o del arte en la vida como habrían intentado ciertas vanguardias artísticas (surrealismo) o políticas (el "arte total” del na- 
cionalsocialismo). A través del concepto de "situación", se trata de pensar el umbral de transfiguración en el que arte y vida devienen indistinguibles (Formis, 2008). No se trata entonces ni de "arte" ni de "vida" sino de un "punto de indiferencia" o, como diría Furio Jesi, un "punto de intersección" en que tanto el arte y la vida se trastocan completamente (Jesi, 2014). Al devenir "indistinguibles" no solo no hay conciliación entre ambas, sino que se abre una esfera completamente diferente más allá del arte y de la propia vida.

El gesto sería, entonces, un "hacer" que no cabe en la nomenclatura del "arte", pero tampoco cabe expresarla como simple "vida" porque el gesto es precisamente una vida que habita los medios puros, y, en este sentido, un campo en que la estética y la política se transfiguran en la cuestión que interesa verdaderamente a Agamben: la ética como una pura exposición de la potencia. Pero al hacer esto así deberíamos precisar en torno a la cuestión de la imagen: al exhibir al gesto en su "medialidad pura", la imagen no es una simple representación, sino una verdadera experiencia. Este es el punto que enlaza irreductiblemente el trabajo de Agamben con la otrora gnoseología averroísta: así como el gesto abre un tercer lugar respecto del arte y la política, la imagen deviene un lugar de experiencia que los seres humanos pueden habitar porque, a diferencia de las imágenes del espectáculo, ellas irrumpen enteramente vivas: "Las imágenes son, por tanto, un elemento resueltamente histórico; pero, de acuerdo con el principio benjaminiano en virtud del cual hay vida en todo aquello en que hay historia (y que podría reformularse en el sentido de que hay vida en todo aquello en que hay imagen), aquéllas están, de alguna manera, vivas" (Agamben, 2007: 54).

En esto, precisamente consiste la vida "ninfal”, según la cual, la "vida es puramente histórica" y toda imagen no es más que una vida. Por esta razón: "La historia de la humanidad es siempre historia de fantasmas e imágenes [...] las imágenes son el resto, la 
huella de todo lo que los hombres que nos han precedido han esperado y deseado, temido y rechazado" (Agamben, 2007: 57). Nada más averroísta que abrazar la idea de que la historia no es la de los "hombres" sino la de sus imágenes. En cuanto "vivas" ellas devienen resto de lo deseado y temido, de la enorme aventura que significa habitar el mundo.

Ahora bien, ¿qué hacemos cuando hacemos?, ¿qué es el hacer?, son las preguntas de la filosofía, aquellas que en parte- a través de un cierto Guy Debord- Agamben no ha dejado de plantear. Por eso, acaso siguiendo la intuición de Georges Bataille y su discusión en torno al problema de la negatividad con Alexandre Kojève en torno a la cuestión del "fin de la historia", Agamben encuentra que al final de la filosofía no nos espera la verdad, sino la risa, no el sacrificio sino la praxis libre (Agamben, 2003): en cuanto forma-devida, el gesto permanece como resto -junto a la imagen que es su "ninfa" - a la clausura histórico-ontológica del espectáculo, exceso de una vida "clandestina" que constituirá el "secreto" más decisivo para pensar la política que viene.

\section{Bibliografía}

Agamben, Giorgio, 2001, "Glosas marginales a los Comentarios sobre la sociedad del espectáculo", en Medios sin fin. Notas sobre la politica, Antonio Gimeno Cuspinera (trad.), Pre-textos, Valencia, pp. 63-78.

2003, Homo sacer. El poder soberano y la nuda vida, Antonio Gimeno Cuspinera (trad.), Ed. Pre-textos, Valencia, pp. 268.

,2003, El lenguaje y la muerte. Un Seminario acerca del lugar de la negatividad, Pre-textos, Valencia. 
2007, Il Regno e la Gloria. Per una genealogía teológica dell'economia e del governo. Homo sacer II, vol. 2, Neri Pozza, Vicenza.

, 2007, "Ninfe", Bollati Boringhieri, Torino.

Torino.

, 2008, Signatura Rerum. Sul Metodo, Bollati Boringhieri, 2014, L'Uso dei corpi. Homo sacer IV, vol. 2, Neri Pozza, Vicenza.

Debord, Guy, 2002, La sociedad del espectáculo, José Luis Pardo (pról., trad., y notas), Pre-textos, Madrid.

, 2009, Panegírico, t. I-II, Greil Marcus (pról.), Mireya Hernández Pozuelo (trad. pról.), Tomás González y Amador Fernández-Savater ((trad. t. I), Álvaro García-Ormaechea (trad. t. II), Ed. Acuarela/Antonio Machado, Madrid.

Jesi, Furio, 2014, Spartakus. Simbologia de la revuelta, Andrea Cavalletti (ed.), Maria Teresa D Mezza (trad.), Ed. Adriana Hidalgo, Buenos Aires.

Formis, Barbara, 2008, "Dismantling Theatricality: Aesthetics of Bare Life", en The Work of Giorgio Agamben. Law, Literature, Life, Justin Clemens, Nicholas Heron, Alex Murray (eds.), Edinburgh University Press, Edimburgo, pp. 181-192.

Foucault, Michel, 2006, Seguridad, Territorio, Población, Cursos en el Collège de France 1978.

Levitt, Deborah, 2008, "Notes on Media and Biopolitics: "Notes on Gesture", en The Work of Giorgio Agamben. Law, Literature, Life, Justin Clemens, Nicholas Heron, Alex Murray (eds.), Edinburgh University Press, Edimburgo, pp. 193-2011.

Schmitt, Carl, 2009, Los fundamentos histórico-espirituales del parlamentarismo, Tecnos, Madrid. 
Prozorov, Sergei, 2016, "Agamben, Badiou and Affirmative Biopolitics", en Agamben and Radical Politics, Daniel McLoughlin (ed.), Critical Connections, Edinburgh University Press, Edimburgo, pp. 165-188. 